\title{
Erratum to: Preventing Inguinodynia After Hernia Surgery: Does the Type of Mesh Matter?
}

Nehal S. Shah · Catherine Fullwood •

Ajith K. Siriwardena $\cdot$ Aali J. Sheen

Published online: 19 December 2014

(C) Société Internationale de Chirurgie 2014

\section{Erratum to: World J Surg}

DOI 10.1007/s00268-014-2837-z

The authors of this Reply, Letter to the Editor are correct as presented in this erratum.

The online version of the original article can be found under doi:10.1007/s00268-014-2837-z.

N. S. Shah · A. K. Siriwardena · A. J. Sheen $(\square)$

Department of Surgery, Manchester Royal Infirmary, University

of Manchester, Oxford Road, Manchester M13 9WL, UK

e-mail: aali.sheen@cmft.nhs.uk

N. S. Shah

e-mail: nehal.shah1@nhs.net

C. Fullwood

Manchester Academic Health Science Centre, Central

Manchester University Hospitals NHS Foundation Trust, NIHR

Manchester Biomedical Research Centre, The University of

Manchester, Manchester, UK 